\title{
Curvature Analysis in Fiber Optic Cables as a Tilt Sensor Based on Macro Bending
}

\author{
Imam Mulyanto ${ }^{1^{*}}$,Syahrul Humaidi ${ }^{2}$, Roy Efendy Sihotang ${ }^{3}$ \\ ${ }^{I}$ Physics Research Center - Indonesian Institute of Sciences (LIPI), PUSPIPTEK Region, South \\ Tangerang, Indonesia 15314 \\ ${ }^{2,3}$ Department of Physics, Faculty of Mathematics and Natural Science, Universitas Sumatera Utara \\ 20155, Indonesia
}

\begin{abstract}
The test has been successfully carried out on optical fibers to be used as a macrobending tilt sensor using SMF-28 single mode optical fiber. The optical fiber was molded with silicon rubber, then connected to a laser light and a power meter to see the intensity of the laser power produced. The principle is carried out using the macro bending phenomenon on single mode optical fibers, where the laser light intensity in the fiber optic cable will decrease if there is a bend or bending in the fiber optic cable. We can observe the power loss resulting from the macro bending process to find out how sensitive the optical fiber is to changes in a given angle. The resulting optical fiber sensitivity value is $-0.1534^{\circ} / \mathrm{dBm}$.
\end{abstract}

Keyword: Optical Fiber, Tilt Sensor, Laser, Macro Bending.

Received 01 July 2020 | Revised [15 July 2020] | Accepted [27 August 2020]

\section{Introduction}

The development of fiber optic technology in the field of telecommunications, computer applications, industry, medical equipment (medical instrument) as well as in the field of military and public applications. In the telecommunications sector, optical fiber is used as a trunk line, backbone, junction routes, submarine cables, and subscriber loops, as well as a channel between computers (LANs), and as a cable TV channel. Optical fiber can also be used as a sensor for measuring pressure, the presence or absence of an object, and temperature [1-2].

Fiber optic technology is a communication network system where the sending and receiving of information signals in the form of light beams. These thin fibers are arranged in bundles called fiber optic cables. Fiber optic cable functions to transmit light without experiencing light loss. Light has been sent from one place to another, experiencing very little signal loss [2]. Optical fibers are very thin, pure optical strands, which are as thin as a human hair. Optical fiber

*Corresponding author at: PUSPIPTEK Region,

South Tangerang, Indonesia 15314

E-mail address: imam004@lipi.go.id 
functions to carry digital information data for long distances. The working principle uses the principle of perfect reflection (total internal reflection) by taking advantage of the difference in the refractive index between the core layer, or its cladding [3]. The advantages of optical fiber as a sensor are that it does not come into direct contact with the measuring object, does not use electricity as a signal, has high measurement accuracy, and its small size [4].

Optical fiber is an application of the concept of light propagation in optical medium. It is difficult for the light inside the optical fiber to come out because the refractive index of glass is greater than the refractive index of air. Examples of light sources that can be used are LASER and LED, because they have a very narrow spectrum. Optical fiber is not only developed in the field of communication but is also used in various components of sensor manufacturing. The advantages of fiber optic sensors compared to other types of sensors are more precision, no interference with EMI, low noise, low required power supply and the power supply can be located far from the location [5-6]. One example of the tilt angle sensor used is the MEMS (Micro Electro Mechanical system) sensor. MEMS sensors are used to measure acceleration, position, or shock. The MEMS development of the accelerometer in the inclinometer is based on the slope reading obtained from the static conditions of the acceleration due to gravity measurement. The inclinometer is used by burying it in the soil through a grooved pipe for the inclinometer line. If there is movement in the soil layer, the pipe containing the inclinometer will experience bending. The inclinometer will measure the angle of inclination of the pipe to the normal angle of the ground surface so that information on how much soil displacement occurs at a certain depth point will be obtained. However, the use of this application is portable, so it must be done periodically and continuously by visiting certain observation points directly.

The use of MEMS accelerometers for sensors on the inclinometer for ground motion observation is quite important. This sensor has the ability to read the slope on each axis which is indicated by the output voltage. Readings on the slope of each axis have no effect on different axes. MEMS The accelerometer is also known as the inclinometer sensor [7-8]. The design, realization and characterization of the tilt sensor in the form of a Micro Electro Mechanical System (MEMS) based on piezoelectric sensors has been developed by Lijun Tang, et. al. 2009, where the system has been characterized and is able to obtain a sensitivity of $0.025 \mathrm{mV} /{ }^{\circ} 2$ ).

Optical fiber inclinometer is a measuring instrument used to measure the slope of a field. This tool can be used as a sensor for the slope of an area in the ground which can be seen from the change in angle. There are two types of bending that cause losses in the fiber, namely micro bending and macro bending. These two types arise for different reasons, and cause losses by two different mechanisms. Curvature is one of the causes of laser transmission losses in optical fibers. In the event of a curve of a certain diameter, not all lasers will be guided by an optical fiber, but some will come out as a result of the change in angle of incidence that has exceeded the critical angle. When the fiber optic curve is made with a smaller diameter, the angle of 
incidence becomes smaller so that many lasers come out and cause the laser intensity to be weaker [9-10].

One of the main factors in the use of optical fiber is its immunity to electromagnetic interference, where the light signal traveling in the optical fiber is not affected by the electromagnetic field. The light inside the optical fiber is difficult to get out because the refractive index of glass is greater than the refractive index of the air, besides that it can be used in humid or wet environments and can be used in deep ground. The disadvantages of this optical fiber are that it has a narrow angle range, exponential curve, and weak optical fiber construction so that in its use, a reinforcing layer is required as protection. Based on the background and the case study, this research will study fiber optic cables for tilt sensor applications based on macro bending with the optical source used, namely lasers with a wavelength of $1310 \mathrm{~nm}$.

\section{Methods}

This study conducted tests on optical fibers to serve as a tilt sensor based on macro bending using a single mode optical fiber SMF-28. Optical fiber is made from molding silicon rubber first, then connected to a laser light and a power meter to see the intensity of the laser power produced.

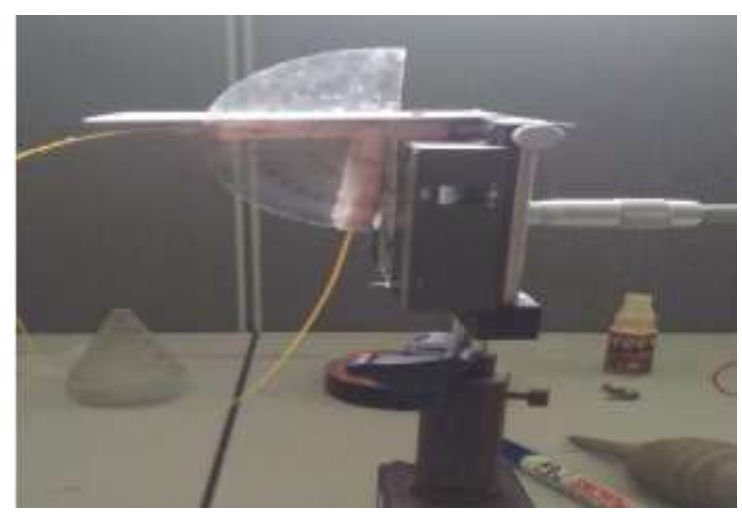

Figure 1. Set up Experiment

An optical fiber in the area of silicone rubber with a certain length is bent by turning the screw micrometer constantly. If pressure is applied to the plane of the screw micrometer, the optical fiber will bend in the same state to the stressed plane, resulting in transmission losses. Data is taken from the change in the optical fiber tilt angle in the field and the intensity of the laser transmitted on the optical fiber by measuring it using a power meter and digital multimeter. 


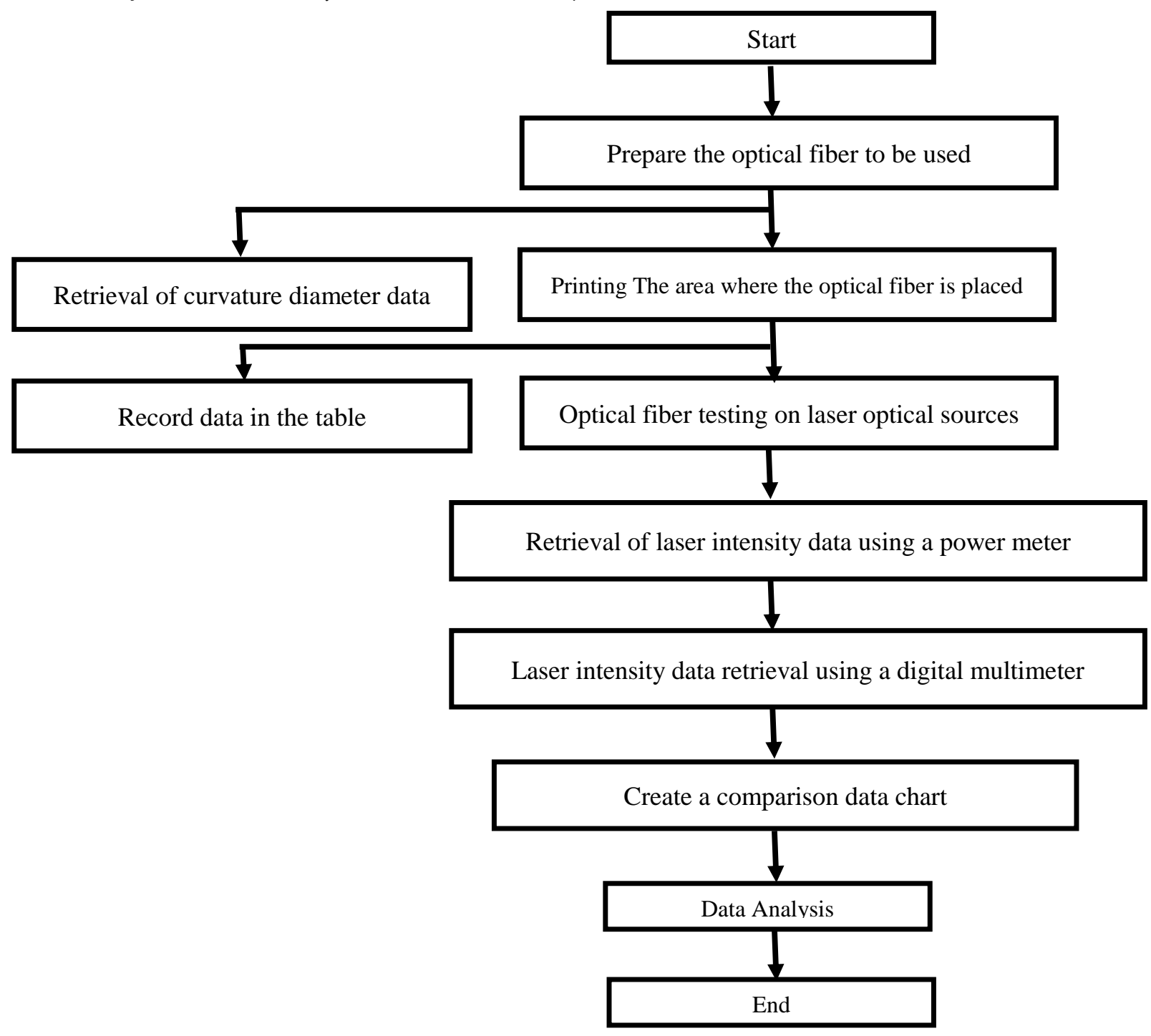

Figure 2. Flowchart of the experiment

\section{Result and Discussion}

The optical fiber used in this study is a single mode type with the brand or type SMF-28 (TM) Fiber. The variation of the bended diameter of the optical fiber used in this study was measured using acrylic. The measurement results on the diameter of acrylic obtained are $55 \mathrm{~mm}, 50 \mathrm{~mm}$, $45 \mathrm{~mm}, 40 \mathrm{~mm}, 35 \mathrm{~mm}, 30 \mathrm{~mm}, 25 \mathrm{~mm}, 20 \mathrm{~mm}, 15 \mathrm{~mm}$.

Furthermore, the results of data retrieval of laser intensity on the power meter through the curved diameter of the optical fiber in acrylic are shown in Table 1. The results of the input power on the laser through the optical fiber are $3 \mathrm{~mW}$. 
Table 1. Laser Intensity Measurement Results for the Bend Diameter of the SMF-28 (TM)

Fiber

\begin{tabular}{ccc}
\hline No. & Diameter $(\mathrm{mm})$ & Laser Intensity $(\mu \mathrm{W})$ \\
\hline 1 & Straight & 590.2 \\
2 & 55 & 589.8 \\
3 & 50 & 589.5 \\
4 & 45 & 588.7 \\
5 & 40 & 588.2 \\
6 & 35 & 587.9 \\
7 & 30 & 587.1 \\
8 & 25 & 584.3 \\
9 & 20 & 562.0 \\
10 & 15 & 455.4 \\
\hline
\end{tabular}

From Table 1, it can be seen that there is a decrease in the value of the laser intensity due to changes in the diameter of the optical fiber curve which is getting smaller at a diameter of 15 $\mathrm{mm}$. This condition indicates that the sensitivity occurs at a diameter of $15 \mathrm{~mm}$.

Then the results of taking the laser intensity data on the power meter through the change in angle of the optical fiber are shown in Table 2 to Table 4.

Table 2. Measurement Results I Laser Intensity SMF-28 (TM) Fiber

\begin{tabular}{ccc}
\hline No & Change in angle $\left(^{\circ}\right)$ & Laser Intensity $(\mu \mathrm{W})$ \\
\hline 1 & 0 & 437.8 \\
2 & 1 & 422.3 \\
3 & 2 & 412.3 \\
4 & 3 & 406.0 \\
5 & 4 & 354.6 \\
6 & 5 & 341.3 \\
7 & 6 & 314.2 \\
8 & 7 & 314.0 \\
9 & 8 & 295.2 \\
10 & 9 & 288.3 \\
11 & 10 & 292.5 \\
12 & 11 & 290.9 \\
13 & 12 & 278.8 \\
14 & 13 & 257.7 \\
15 & 14 & 260.3 \\
16 & 15 & 259.0 \\
\hline
\end{tabular}


Table 3. Measurement Results II of SMF-28 (TM) Fiber Laser Intensity

\begin{tabular}{ccc}
\hline No & Change in Angle $\left(^{\circ}\right)$ & Laser Intensity $(\mu \mathrm{W})$ \\
\hline 1 & 0 & 436.4 \\
2 & 1 & 418.7 \\
3 & 2 & 410.6 \\
4 & 3 & 408.5 \\
5 & 4 & 399.8 \\
6 & 5 & 399.6 \\
7 & 6 & 356.4 \\
8 & 7 & 342.0 \\
9 & 8 & 319.9 \\
10 & 9 & 317.6 \\
11 & 10 & 303.5 \\
12 & 11 & 288.9 \\
13 & 12 & 288.0 \\
14 & 13 & 286.3 \\
15 & 14 & 289.4 \\
16 & 15 & 272.4 \\
\hline
\end{tabular}

Table 4 Measurement Results III of SMF-28 (TM) Fiber Laser Intensity

\begin{tabular}{ccc}
\hline No & Change in Angle $\left(^{\circ}\right)$ & Intensitas Laser $(\mu \mathrm{W})$ \\
\hline 1 & 0 & 429.2 \\
2 & 1 & 418.3 \\
3 & 2 & 403.5 \\
4 & 3 & 402.2 \\
5 & 4 & 395.8 \\
6 & 5 & 351.6 \\
7 & 6 & 324.6 \\
8 & 7 & 340.7 \\
9 & 8 & 317.9 \\
10 & 9 & 302.8 \\
11 & 10 & 282.9 \\
12 & 11 & 285.9 \\
13 & 12 & 285.8 \\
14 & 13 & 287.9 \\
15 & 14 & 267.5 \\
16 & 15 & 255.6 \\
\hline
\end{tabular}

The results of this study indicated the measurement of the laser intensity on the optical fiber of SMF-28 (TM) fiber. Measurements were made by repetition of 3 times the experiment. In the first measurement to the third measurement, the laser intensity value is not much different when the angle change occurs in the optical fiber SMF-28 (TM) Fiber. 
Table 5. Result of Converting Laser Intensity Power $(\mu \mathrm{W})$ To dBm

\begin{tabular}{cccccc}
\hline \multirow{2}{*}{ No } & $\begin{array}{c}\text { Change in } \\
\text { Angle }\left({ }^{\circ}\right)\end{array}$ & \multicolumn{4}{c}{ Power Conversion $(\mathrm{dBm})$} \\
& 0 & -3.59 & -3.60 & -3.63 & -3.60 \\
\hline 1 & 1 & -3.80 & -3.77 & -3.91 & -3.82 \\
2 & 2 & -3.88 & -3.87 & -3.88 & -3.87 \\
3 & 3 & -3.92 & -3.92 & -3.96 & -3.93 \\
4 & 4 & -4.34 & -3.96 & -4.02 & -4.10 \\
5 & 5 & -4.62 & -3.95 & -4.52 & -4.36 \\
6 & 6 & -5.01 & -4.43 & -4.83 & -4.75 \\
7 & 7 & -5.01 & -4.60 & -4.67 & -4.76 \\
8 & 8 & -5.27 & -4.90 & -4.96 & -5.04 \\
9 & 9 & -5.39 & -4.95 & -5.22 & -5.18 \\
10 & 10 & -5.36 & -5.14 & -5.46 & -5.32 \\
11 & 11 & -5.36 & -5.39 & -5.45 & -5.40 \\
12 & 12 & -5.47 & -5.41 & -5.49 & -5.45 \\
13 & 13 & -5.94 & -5.42 & -5.37 & -5.57 \\
14 & 14 & -5.97 & -5.41 & -5.65 & -5.67 \\
15 & 15 & -5.96 & -5.52 & -5.82 & -5.76 \\
16 & & & & & \\
\hline
\end{tabular}

Table 5 shows the results of laser intensity measurements that have been converted into $\mathrm{dBm}$ units on the optical fiber SMF-28 (TM) Fiber. Measurements were made by repetition of 3 times the experiment. In the first measurement to the third measurement, the laser intensity value is not much different when the angle change occurs in the optical fiber SMF-28 (TM) Fiber. In this power conversion, the results of unstable data are obtained.

Table 6. Laser Voltage Results Using a Digital Multimeter I

\begin{tabular}{ccc}
\hline No & Change in Angle $\left(^{\circ}\right)$ & Voltage $($ V) \\
\hline 1 & 0 & 3.06 \\
2 & 1 & 2.94 \\
3 & 2 & 2.89 \\
4 & 3 & 2.88 \\
5 & 4 & 2.83 \\
6 & 5 & 2.86 \\
7 & 6 & 2.34 \\
8 & 7 & 2.22 \\
9 & 8 & 2.16 \\
10 & 9 & 2.07 \\
11 & 10 & 2.04 \\
12 & 11 & 2.09 \\
13 & 12 & 2.08 \\
14 & 13 & 2.03 \\
15 & 14 & 1.97 \\
16 & 15 & 1.86 \\
\hline
\end{tabular}


Table 7. Laser Voltage Results Using a Digital Multimeter II

\begin{tabular}{ccc}
\hline No & Change in Angle $\left(^{\circ}\right)$ & Voltage $(\mathrm{V})$ \\
\hline 1 & 0 & 3.13 \\
2 & 1 & 2.95 \\
3 & 2 & 2.90 \\
4 & 3 & 2.86 \\
5 & 4 & 2.84 \\
6 & 5 & 2.82 \\
7 & 6 & 2.84 \\
8 & 7 & 2.74 \\
9 & 8 & 2.60 \\
10 & 9 & 2.37 \\
11 & 10 & 2.39 \\
12 & 11 & 2.45 \\
13 & 12 & 2.36 \\
14 & 13 & 2.28 \\
15 & 14 & 2.24 \\
16 & 15 & 2.15 \\
\hline
\end{tabular}

Table 8. Results of Laser Voltage Using a Digital Multimeter III

\begin{tabular}{ccc}
\hline No & Change in Angle $\left(^{\circ}\right)$ & Voltage $(\mathrm{V})$ \\
\hline 1 & 0 & 3.13 \\
2 & 1 & 3.08 \\
3 & 2 & 2.98 \\
4 & 3 & 2.92 \\
5 & 4 & 2.91 \\
6 & 5 & 2.89 \\
7 & 6 & 2.92 \\
8 & 7 & 2.80 \\
9 & 8 & 2.66 \\
10 & 9 & 2.52 \\
11 & 10 & 2.42 \\
12 & 11 & 2.41 \\
13 & 12 & 2.42 \\
14 & 13 & 2.38 \\
15 & 14 & 2.30 \\
16 & 15 & 2.24 \\
\hline
\end{tabular}

Table 6-8 show the results of measuring the laser intensity voltage to the change in angle in the optical fiber SMF-28 (TM) Fiber. Measurements were made by repetition of 3 times the experiment. In the first measurement to the third measurement, the voltage value decreases, which can be concluded that the optical fiber patch cord experiences transmission losses when the angle changes. 


\section{Conclusion}

The effect of the bending diameter on the optical fiber of the SMF-28 (TM) Fiber, namely if the smaller the diameter of the optical fiber, the intensity of the laser produced will decrease or decrease. A significant reduction in laser intensity occurred at a diameter of $15 \mathrm{~mm}$. The results of the analysis and discussion obtained that the optical fiber SMF-28 TM can be used as a tilt sensor, but the resulting value is not accurate or sensitive to changes in angle. The optical fiber of the SMF-28 TM brand after being treated with silicone rubber molding produces a sensitivity of $-0.1534^{\circ} / \mathrm{dBm}$.

\section{REFERENCES}

[1] Hariyadi, Sistem Komunikasi Fiber Optik Dan Pemanfaatannya Pada PT. Semen Padang. Rang Teknik Journal. I, No.1: 43-51, 2018.

[2] Kumar. S, Deen. M, Fiber Optic Communications Fundamentals And Applications, John Wiley \& Sons, Canada, 2014.

[3] S. Addanki, I. S. Amiri, and P. Yupapin, "Review of optical fibers-introduction and applications in fiber lasers", Results in Physics, vol. 10, pp.743-750, 2018.

[4] B. Lee, "Review of the present status of optical fiber sensors. Optical fiber technology", vol.9, no.2, pp.57-79, 2003.

[5] Mulyanto. I, Bayuwati. D, Widiyatmoko. B, Rancang Bangun Dan Karakterisasi Sensor Pendeteksi Kemiringan Pipa Vertikal Didalam Tanah Berbasis Serat Optik. Di dalam, Kawasan PUSPIPTEK, Serpong Pusat Penelitian Fisika-LIPI. Seminar Nasional Riset dan Teknologi, Jakarta, Tangerang Selatan: Pusat Penelitian Fisika-LIPI, 253-258, 2018.

[6] Hanto. D, Widiyatmoko. B, Perancangan Sensor dan Antarmuka Inklinometer Waktu Nyata, Di dalam: Grup Tera Hertz Photonics-Bidang Instrumentasi Fisis dan Optoelektronika. Prosiding Pertemuan Ilmiah XXVI HFI Jateng \& DIY, Purworejo, Tangerang Selatan, Pusat Penelitian Fisika- LIPI, 114-117, 2012.

[7] R. Bogue, "Recent developments in MEMS sensors: A review of applications, markets and technologies", Sensor Review, 2013.

[8] S. Beeby, G. Ensel, N. M. White, and M. Kraft, MEMS mechanical sensors, Artech House, 2004.

[9] H. F. Pei, J. H. Yin, and W. Jin, "Development of novel optical fiber sensors for measuring tilts and displacements of geotechnical structures", Measurement Science and Technology, vol. 24, no. 9, pp.095202, 2013.

[10] H. Wu, Y. Guo, L. Xiong, W. Liu, G. Li, and X. Zhou, "Optical fiber-based sensing, measuring, and implementation methods for slope deformation monitoring: a review", IEEE Sensors Journal, vol. 19, no.8, pp.2786-2800, 2019. 